\title{
A comprehensive review of ecosystem research and context analysis in mental health care
}

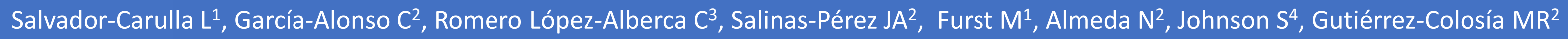

1 Centre for Mental Health Research, Research School of Population Health, ANU College of Health and Medicine, Australian National University, Canberra, Australia; 2 Universidad Loyola Andalucía, Sevilla, Spain; 3 Department of Psychology, University of Cádiz, Cádiz, Spain; 4 Division of Psychiatry, University College London, London, UK

\section{Background and Aims:}

The role of context is critical in health services research. In health care, "context" could be defined as all sources of evidence of the local system: geographic, social and demographic factors, other environmental factors, service availability and scope, capacity, use, costs and the historical development of the health care system. The analysis of context of care of "healthcare ecosystem research" is an emerging discipline that should play a critical role in implementation sciences [1] and in the analysis of complex interventions [2, 3]. "Contextual evidence" has recently been identified as a major source of knowledge in health systems research together with experimental, observational, expert and experiential knowledge [4]. In spite of its relevance, the need for context analysis in health services and delivery research has not been sufficiently recognised $[1,2,4]$. One of the most widely used instrument in context analysis providing data on service availability is ESMS/DESDE (Description and Evaluation of Services and Directories for Long Term Care.

This piece of research aims 1) to analyse available methods of context analysis and healthcare ecosystem research for standard description of mental health $(\mathrm{MH})$ systems and services; 2) to analyse the gaps in the literature; .3) to review the use and impact of the ESMS/DESDE system for service research and policy making.

\section{Material and Methods:}

Two literature reviews have been carried out. First, a scoping review on methods and instruments for standard description of mental health service delivery. Second, a systematic review of the system better suited for this type of research following the PRISMA guidelines [5].

\section{Results:}

The scoping review [6] identified 46 papers that fulfilled inclusion criteria and 6 instruments for context analysis: ESMS/DESDE, WHO-AIMS, MHCP, PROMO, PRIME and ASME (Table). The ESMS/DESDE was the better suited for local context analysis and its aggregation to national level. The systematic review of ESMS/DESDE [7] identified 155 papers that mentioned the system in the scientific literature and 71 used it for service research and planning. The evolution of the system from year 2000 is showed below.
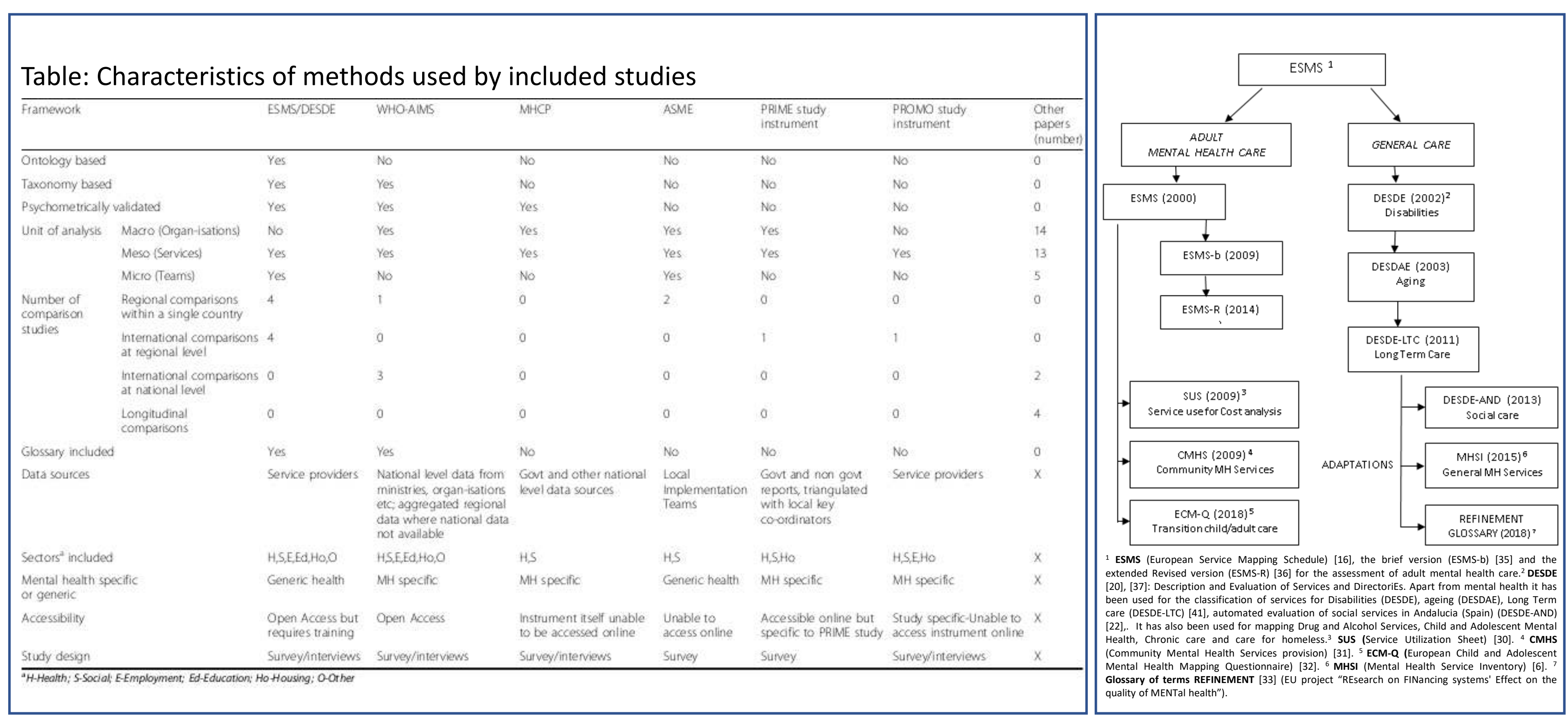

\section{Conclusions:}

In general, the challenges of commensurability, of terminological variability, and of data availability and validity which face this area of research are poorly addressed, with few standardized frameworks available. This presents a barrier to valid system comparison, particularly across regions or countries, where regional and historical variations in service provision increase terminological variability.

ESMS/DESDE is readily accessible and validated, and takes both a local approach and a whole bottom-up systems perspective.

We have identified the relevance to this area of research of use of a standardised instrument, formal geographic boundaries, a glossary of terms, formal target populations and a whole systems approach.

\section{References}

1. Lee BY, Wong KF, Bartsch SM, Yilmaz SL, Avery TR, Brown ST, et al. The Regional Healthcare Ecosystem Analyst (RHEA): a simulation modeling tool to assist infectious disease control in a health system. J Am Med Inform Assoc. 2013 Jun 1;20(e1):e139-46.

2. Raine R, Fitzpatrick R, Barratt H, Bevan G, Black N, Boaden R, et al. Challenges, solutions and future directions in the evaluation of service innovations in health care and public health. Health Serv Deliv Res. 2016 May;4(16):1-136.

3. Chung, L Salvador-Carulla, J Salinas-Perez, J Uriarte-Uriarte, A Iruin-Sanz, CR García-Alonso. Use of the Self-Organising Map Network (SOMNet) as a Decision Support System for Regional Mental Health Planning. Health Res Policy Syst. 2018

4. Salvador-Carulla L, Lukersmith S, Sullivan W. From the EBM pyramid to the Greek temple: a new conceptual approach to Guidelines as implementation tools in mental health. Epidemiol Psychiatr Sci. 2017;26(2):105-14

5 D. Moher, A. Liberati, J. Tetzlaff, D.G. Altman, \& The PRISMA Group. Preferred reporting items for systematic reviews and meta-analyses: the PRISMA statement. Annals of internal medicine, 151(4) (2009)

6. Furst MA : Gandré C, Romero López-Alberca C, Salvador-Carulla L (2019) Healthcare ecosystems research in . Furst MA, Gandré C, Romero López-Alberca C, Salvador-Carulla L (2019) Healthcare ecosystems research in 19:173. doi: 10.1186/s12913-019-4005-5 (2.

7. Romero-López-Alberca C, Gutierrez-Colosía MR, Salinas-Pérez JA, Almeda N, Furst M, Johnson S, SalvadorCarulla $L$. Standardised description of health and social care. a systematic review of use of the ESMS/DESDE (European Service Mapping Schedule / Description and Evaluation of Services and DirectoriEs). European calstralian) National of LOYOLA =IICL 